\title{
Trace metal analysis in arctic aerosols by an inductively coupled plasma-time of flight-mass spectrometer combined with an inductively heated vaporizer
}

\author{
Christian Lüdke ${ }^{\mathrm{a}, *}$, Jochen Skole ${ }^{\mathrm{a}}$, Kerstin Taubner ${ }^{\mathrm{a}}$, Michael Kriews ${ }^{\mathrm{b}}$ \\ a ISAS - Institute for Analytical Sciences, Department Berlin, Albert-Einstein-Str. 9, 12489 Berlin, Germany \\ b Alfred Wegener Institute for Polar-and Marine Research, Am Handelshafen 12, 27570 Bremerhaven, Germany
}

Received 24 February 2005; accepted 17 August 2005

\begin{abstract}
Two newly developed instruments were combined to analyze the trace metal content in size separated arctic aerosols during the measurement campaign ASTAR 2004 (Arctic Study of Tropospheric Aerosols, Clouds and Radiation 2004) at Spitsbergen in May-June 2004. The aim of this extensive aerosol measurement campaign was to obtain a database for model-calculations of arctic aerosol, which play an important role in the global climate change. The ASTAR project was centered on two aircraft measurement campaigns, scheduled from 2004 to 2005 , addressing both aerosol and cloud measurements, combined with ground-based and satellite observations. In the present paper one example for the analysis of ground-based aerosol particles is described. The sampling of aerosol particles was performed in a well-known manner by impaction of the particles on cleaned graphite targets. By means of a cascade impactor eight size classes between 0.35 and $16.6 \mu \mathrm{m}$ aerodynamic diameters were separated. To analyze the metal content in the aerosol particles the targets were rapidly heated up to $2700{ }^{\circ} \mathrm{C}$ in an inductively heated vaporizer system (IHVS). An argon flow transports the vaporized sample material into the inductively coupled plasma (ICP) used as ionization source for the time of flight-mass spectrometer (TOF-MS). The simultaneous extraction of the ions from the plasma, as realized in the TOF instrument, allows to obtain the full mass spectrum of the sample during the vaporization pulse without any limitation in the number of elements detected. With optimized experimental parameters the element content in arctic aerosol particles was determined in a mass range between ${ }^{7} \mathrm{Li}$ and ${ }^{209} \mathrm{Bi}$. Comparing the size distribution of the elemental content of the aerosol particles, two different meteorological situations were verified. For calibration acidified reference solutions were placed on the cleaned target inside the IHVS. The limits of detection (LOD) for the element mass on the target range between 2 and 200 pg for the elements studied, except $\mathrm{Na}, \mathrm{Mg}$, and $\mathrm{Cr}$, which are influenced by high background.
\end{abstract}

(C) 2005 Elsevier B.V. All rights reserved.

Keywords: Solid sample analysis; Size classified atmospheric particles; Vaporization by inductive heating; Fast transient signal; TOF mass spectrometer

\section{Introduction}

Inductively coupled plasma mass spectrometry (ICP-MS) is a convenient method to analyze elements and isotopes [1-3]. In modern analytical mass spectrometry, the efficient simultaneous determination of multiple chemical elements of microscopically amount of samples still represents a challenge. Basically, the two most common types of mass spectrometers like quadrupole - or sector-field-instruments operate as sequential filters for single masses. Consequently, to perform multielement analyses in multi component samples it only can be carried out by scanning the instrumental mass-defining parameters through the range of the expected element mass that

\footnotetext{
* Corresponding author.

E-mail address: luedke@ansci.de (C. Lüdke).
}

is a time-consuming process. A minimum of 5 to $10 \mathrm{~ms}$ dwelltime is necessary for the determination of each mass. Vaporization of micro samples by an electrothermal or laser pulse and ionizations by an ICP generates transient signals with a width of a few hundreds of ms [4]. Since the typical timescale for scanning through the mass range from, e.g. ${ }^{7} \mathrm{Li}^{+}-{ }^{270} \mathrm{UO}_{2}^{+}$ ( 1 run=263 mass points at $7.5 \mathrm{~ms}$ dwell-time $=2 \mathrm{~s}$ ) is much longer than the duration of a transient signal, the number of detectable elements may be drastically reduced. In order to circumvent such limitations, expensive multicollector devices must be installed. A much more versatile solution is the use of a time of flight-mass spectrometer (TOF-MS). In each measurement cycle (e.g. $40 \mu \mathrm{s}$ ) the ions from all elements will be extracted from the plasma at the same point of time and accelerated into a field-free drift tube by a short repulsive pulse (repeller pulse). The masses are separated by their different 
transition times to a common detector, because their drift velocity is proportional to the square root of their charge-tomass ratio. The counting of ions of different elements by the detector proceeds in a temporal succession but the ions from all elements are sampled from the plasma at exactly the same time [5]. Therefore, in contrast to the quadrupole or sector-field mass spectrometer, the TOF mass spectrometry is a simultaneous technique. ICP-TOF mass spectrometry is relatively new and only few instruments are commercially available [6-9]. The performance of the current ICP-TOF-MS instruments was improved by a specially designed entrance optics with a variable entrance slit. This makes it possible to select a portion of ions with better homogeneity of ion energy. By this way the velocity spread of ions will be reduced, both along and perpendicular to the flight tube, which results in small lines, better resolution and lower background. Based on this improvement an ICP-TOF-MS instrument has been developed and built up in our laboratory and used in the present study [10].

The most common sample introduction system for inductively coupled plasma mass spectrometry-independent of the special type of spectrometer-is solution nebulization, but in order to cover the huge variety of analytical samples also alternative introduction systems are applied which are an active area of research [11-14]. Some disadvantages of solution nebulization are evident. Caused by the inefficiency of the nebulizer-spray chamber a significant portion of the sample is not transported into the ICP but pumped into the drain. The content of water in the plasma gives reason to the production of oxides resulting in isobaric interferences. A popular method to avoid these disadvantages is to introduce the analyte into an ICP as a dry aerosol, e.g., by electrothermal vaporization (ETV). Isobaric interferences caused by aqueous or organic solvents can be reduced because the sample solvent is vaporized before the analyte. Furthermore, thermal pretreatment in a charring step allows volatile matrices to be removed before analyte vaporization.

The procedure for ETV, including the instrumentation and readily handling of small sample volumes, is well-known from graphite furnace atomic absorption spectrometry (GFAAS) $[15,16]$. It is mostly easily adapted for ETV-ICP-MS [17-19] even if the tube form comprises some disadvantages: (i) during the period of heating the tube an argon flow carries the vaporized sample out of the tube through a chilled electrical contact upon which vaporized species may condense, (ii) the electrical heating needs an excellent contact between tube and contact cones provided by the precision of cones and a constant contact pressure, (iii) the relatively high graphite volume needs to clean. To overcome the disadvantages mentioned above an inductively heated vaporizer system (IHVS) was developed. This system involves a small graphite disc-able to take up the sample-arranged in an argon rinsed quartz tube which is surrounded by an induction coil. Applying rf power to the induction coil causes rapid heating of the graphite disc up to $2700{ }^{\circ} \mathrm{C}$ and thereby evaporated sample material is swept into the plasma by an argon carrier gas flow. The rf power is delivered by an $6 \mathrm{~kW}$ solid state rf generator operating at 400
$\mathrm{kHz}$. Graphite is the favored material for inductively heated vaporizer because of its excellent conductivity, resistance against chemical attacks and high temperature stability. The IHVS is a "non contact" heating system which limits possible contaminations from contact cones. Additionally, the evaporation from the so-called "open vaporizer" supports the rapid physical condensation of vaporized material to particles, which can be effectively transported by the carrier gas flow into the plasma [20]. Similar designed inductively heated vaporizer for ICP optical emission spectrometry (OES) [21,22] and mass spectrometry [23] are described, especially to improve sensitivity in ICP-OES using higher sample volumes, which are dried up in a graphite cup. One disadvantage of these arrangements was the tendency to "arcing" that means a discharge between induction coil and graphite sample cup caused by the high operating frequency $(13 \mathrm{MHz})$ of the generator-type used. The "arcing" prevents setting of higher power supply voltage in order to reach higher temperatures. The incomplete energy transfer into the graphite cup underneath the "arcing threshold" results in a maximum temperature of $1900{ }^{\circ} \mathrm{C}$. A method for eliminating arcing is described in a recent paper [24]. The main effect was achieved by replacing the glass tube, surrounding the graphite cup, by a quartz one. Now a temperature of $2600{ }^{\circ} \mathrm{C}$ is specified by setting higher voltage of the power supply.

The aim of this study is the determination of element contents in size fractionated atmospheric particles from the high Arctic by ICP-TOF-MS. The knowledge of the chemical composition of airborne particles improve the interpretation of aerosol properties [25]. In contrast to the determination of size and chemical composition of individual particles with an ATOFMS (aerosol time of flight mass spectrometer) [26] our sampling equipment can be used at low temperatures and in remote areas due to the low power consumption and low weight. In addition the detection limits for the subsequent trace element analyses can be reduced by the variation of the sampling time. A further advantage of our sampling and analyze strategy is the fact that other studies are possible with the obtained sample material: morphological studies were performed by scanning electron microscopy and main components can be analyzed by EDXA (energy-dispersive X-ray analysis) [27]. The determination of trace metals in size fractionated particles of air and car exhaust by electrothermal vaporization combined with ICP-Quadrupole-MS was already described in previous papers [28-30]. A big drawback in these studies was the limitation in the detectable number of isotopes during the vaporization pulse. An additional goal of this study is to demonstrate the simultaneous multi-element analysis of microscopically sample amounts by ICP-TOF-MS combined with an inductively heated vaporizer for solid samples.

\section{Instrumentation}

\subsection{ICP-TOF-MS instrument}

The investigations described here were performed using an in-house manufactured orthogonal acceleration time of flight- 
mass spectrometer [10]. A schematic outline of the ICP-TOFMS instrument is presented in Fig. 1. The combination with an ICP as ionization source accounts for a standard interface containing sampler and skimmer cone. The sample ion stream is focused by a charged second skimmer cone and a single cylinder lens into the instruments entrance slit. The focused ion beam is directed into the repeller space where the orthogonal deflection starts by the repeller pulse. Small instrument dimensions were realized by an asymmetrical flight tube arrangement back and forth $0.6 / 0.1 \mathrm{~m}$ fitted with an ion reflection mirror [31]. To remove unwelcomed ions of argon or matrix elements an ion selector is located at the first space focus point. A pair of comb-shaped electrodes connected with two ultra fast electronic switches generates a transient electric field which deflects a selected narrow range of mass out of the drift path. A maximum of 64 different points in the mass spectrum can be selected and independently switched for suppressing a certain ion mass region. Ion detection is achieved by utilizing the microchannel plate chevron assembly of Burle Technologies, Inc. Lancaster, Pennsylvania, USA. Behind the pre-amplifier a pulse counting electronic device, based on a special developed ASIC-chip (application specific integrated circuit), takes the identification, counting and storage of the incoming pulses.

For our measurements the data acquisition is programmed as follows: the ASIC's read out is a hardware summation of 255 measurement cycles and takes $10.2 \mathrm{~ms}$ at $25 \mathrm{kHz}$ scan frequency. After hardware summation a time of $8.6 \mathrm{~ms}$ is required for data transfer, storage and reset. Hence one sweep

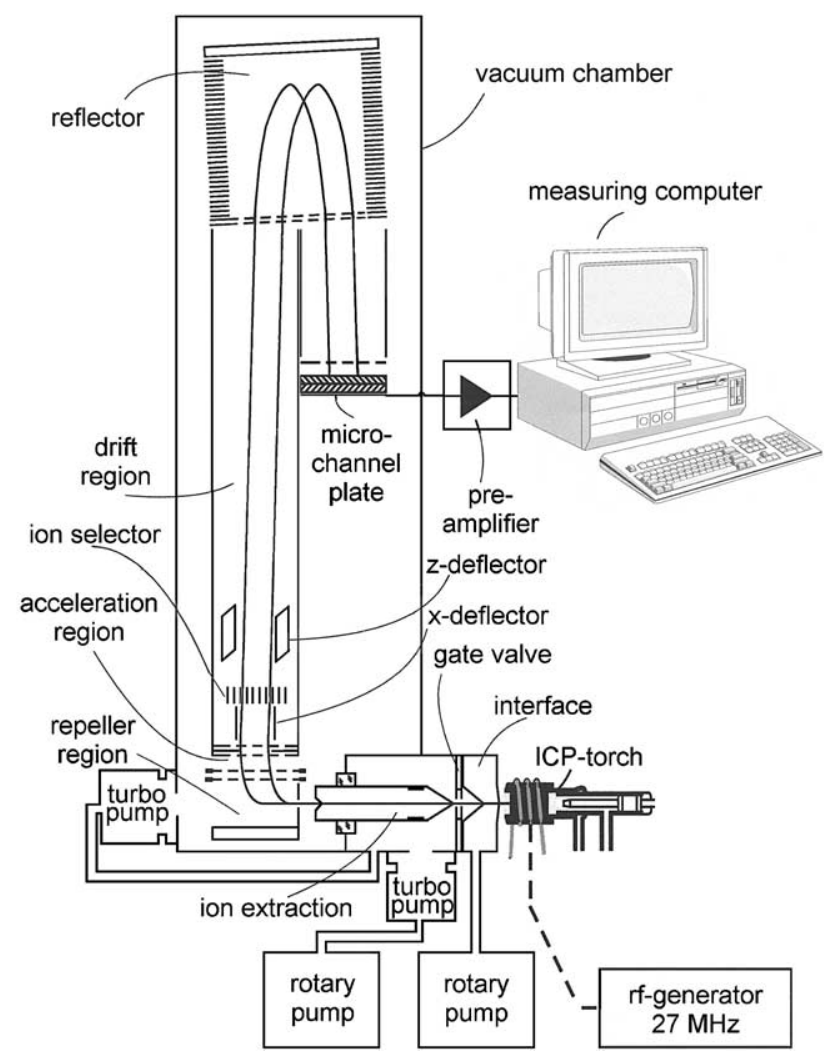

Fig. 1. Schematic outline of the ICP-TOF-MS instrument.
Table 1

ICP-TOF-MS operating settings

\begin{tabular}{llll}
\hline ICP source & & \multicolumn{2}{l}{ Signal measurement by pulse counting } \\
\cline { 3 - 4 } & & Preamplifier \\
\hline RF plasma generator & Solid state & Gain & $21 \mathrm{~dB}$ \\
Frequency & $27.12 \mathrm{MHz}$ & Band width & $1.8 \mathrm{GHz}$ \\
RF power & $1000 \mathrm{~W}$ & Discriminating threshold & $-4 \mathrm{mV}$ \\
Plasma gas flow rate & $141 \mathrm{~min}^{-1}$ & Measuring time & $15 \mathrm{~s}$ \\
Auxiliary gas flow rate & $1.41 \mathrm{~min}^{-1}$ & $(800$ sweeps of $18.8 \mathrm{~ms})$ & \\
Nebulizer gas flow rate & $11 \mathrm{~min}^{-1}$ & Scan frequency & $25 \mathrm{kHz}$ \\
Shield of stainless steel & $17 \mathrm{~cm}^{2}$ & Repeller pulse duration & $2 \mu \mathrm{s}$ \\
& & Ion flow pass duration & $32 \mu \mathrm{s}$ \\
& & Time resolution & \\
& & for pulse counting & $1 \mathrm{~ns}$ \\
\hline
\end{tabular}

needs $18.8 \mathrm{~ms}$ and contains 255 measurement cycles. Data were stored in ASCII-code files. Further data management can be performed by all common data analysis programs.

The inductively coupled plasma, used in combination with the TOF instrument, was generated by a $27.12 \mathrm{MHz}$ solid state generator of Dressler RF Technology, 52224 Stolberg, Germany. The standard quartz torch-load coil design was modified by an electrostatic stainless steel shield between torch and load coil. Grounding the shield after ignition of the plasma results in a minimized bias potential and prevents secondary discharges between plasma and skimmer cone which may have an detrimental effect on ions path way. A different way to minimize the bias potential is to ground the middle of the load coil [32] but its prerequisite is a generator with a symmetrical rf exit. Instrumental settings are summarized in Table 1.

\subsection{Inductively heated vaporizer system}

The principle of high frequency inductive heating is based on an alternating current flowing through an induction coil which creates an alternating magnetic field in its proximity [33]. When electrically conductive materials are introduced into these magnetic fields, secondary currents are induced in the materials resulting in heat near the surface of the workpiece. A lot advantages prefer such a heating system as an analytical vaporizer system: energy transfer occurs without any contact, inductive heating occurs only in the immediate vicinity of the inductor, the high frequency currents $(f>10 \mathrm{kHz})$, induced in the workpiece, are largely concentrated near the surface (skin effect) [34]. In contrast to an electro-thermal heated graphite tube the inductively heated system avoids analyte losses in chilled contact cones, minimizes contaminations by contacts and heats much smaller graphite parts resulting in lower background of trace elements from the graphite. Latter is a real limitation in graphite evaporation systems. Further on, the mechanical contactforces limit the life-time of the tube drastically. An inductively heating system allows to operate an open vaporization cell, characterized by the relative remote distance between the vaporization surface and the enclosing quartz tube [35]. This system seems to be better suited to support the 
Table 2

Optimized conditions for inductively heated vaporizer

\begin{tabular}{ll}
\hline Graphite sample carrier & $13 \mathrm{~mm}$ diam.; $2.5 \mathrm{~mm}$ thick \\
Graphite rod & $3 \mathrm{~mm}$ diam.; $80 \mathrm{~mm}$ long \\
Quartz tube & $18 \mathrm{~mm}$ outer diam.; $1.2 \mathrm{~mm}$ thick; $130 \mathrm{~mm}$ long \\
Maximum temperature & $2750{ }^{\circ} \mathrm{C}$ (controlled by optical pyrometer) \\
Temperature ramp rate & $1000{ }^{\circ} \mathrm{C} \mathrm{s}-1$ \\
Cool down time & $160 \mathrm{~s}$ at $3.51 \mathrm{~min}^{-1}$ gas flow rate \\
Life time & $>1000$ heating cycles \\
\hline
\end{tabular}

aerosol formation by physical condensation of vapour [20], which may reduce losses of evaporated material on the transport into the plasma.

The generator used for the experiments was a solid state rfgenerator type M $260(150-400 \mathrm{kHz}, 6 \mathrm{~kW})$ of Systemtechnik Skorna GmbH, 92237 Sulzbach-Rosenheim, Germany, equipped with a water cooled three turn inductor. Stepwise temperature control was possible by regulating the DC voltage $(0-10 \mathrm{~V})$ applied to the plate of the solid state rfgenerator. The time-temperature scheme needed for the heating cycles was realized by a computer program. The efficiency of induction heating depends among other parameters on the diameter ratio $D / d$ for various workpieces ( $D=$ =inductor diameter, $d=$ =workpiece diameter). To prevent blank values from the graphite, one goal is to heat the smallest possible graphite workpiece which serve as a holder for the sample targets $(6 \mathrm{~mm} \varnothing)$ as described below. The inductor was minimized to dimensions $(20 \mathrm{~mm}$ internal diameter, $4 \mathrm{~mm}$ copper-tube) just compliant to resonant circuit and cooling requirements.

Different shapes of graphite workpieces, in-house manufactured from commercially available graphite (Type EK 93 from SGL Carbon AG, Werk Ringsdorff, Bonn, Germany), were optimized for following parameters: upper temperature limit and shortest temperature rise time as well as minimum size and cooling down period. The goal of optimization is to produce an evaporation peak, small and high, which promises the best signal to noise ratio. Optimal results, summarized in Table 2, are given by an disc-shaped graphite piece of $13 \mathrm{~mm}$ in diameter and $2.5 \mathrm{~mm}$ thick, screwed on a thin graphite rod which is plugged in a Teflon base plate. The Teflon base plate is equipped with the gas inlet for transport- or cooling gas and O-rings to seal a quartz tube (volume $17.4 \mathrm{~cm}^{3}$ ) which surrounds the graphite parts. On top of the quartz tube an O-ring sealed Teflon head-piece connects the vaporization unit to the torch adapter of the ICP via a short flexible Teflon tube. Between the Teflon headpiece and the torch adapter a branch connection was placed, to redirect the flow of Argon transport or cooling gas to an exhaust valve while the sample was dried, pyrolysed or cooled in the graphite workpiece. A curtain gas fills the torch adapter when the vaporization unit is opened for delivering a sample. It prevents the entrance of air which may cause the break down of the plasma. To coordinate the different gas flows, a gas control device was in-house manufactured and operated by a subroutine of the computer program for timetemperature control mentioned above. A scheme of the inductively heated vaporization unit and the gas control device is shown in Fig. 2.

\section{Experimental}

\subsection{Size classified sampling of atmospheric particles}

The detailed sampling procedure has been presented in previous papers [28-30] but only a brief description is given here. The method for collection of airborne particles used in

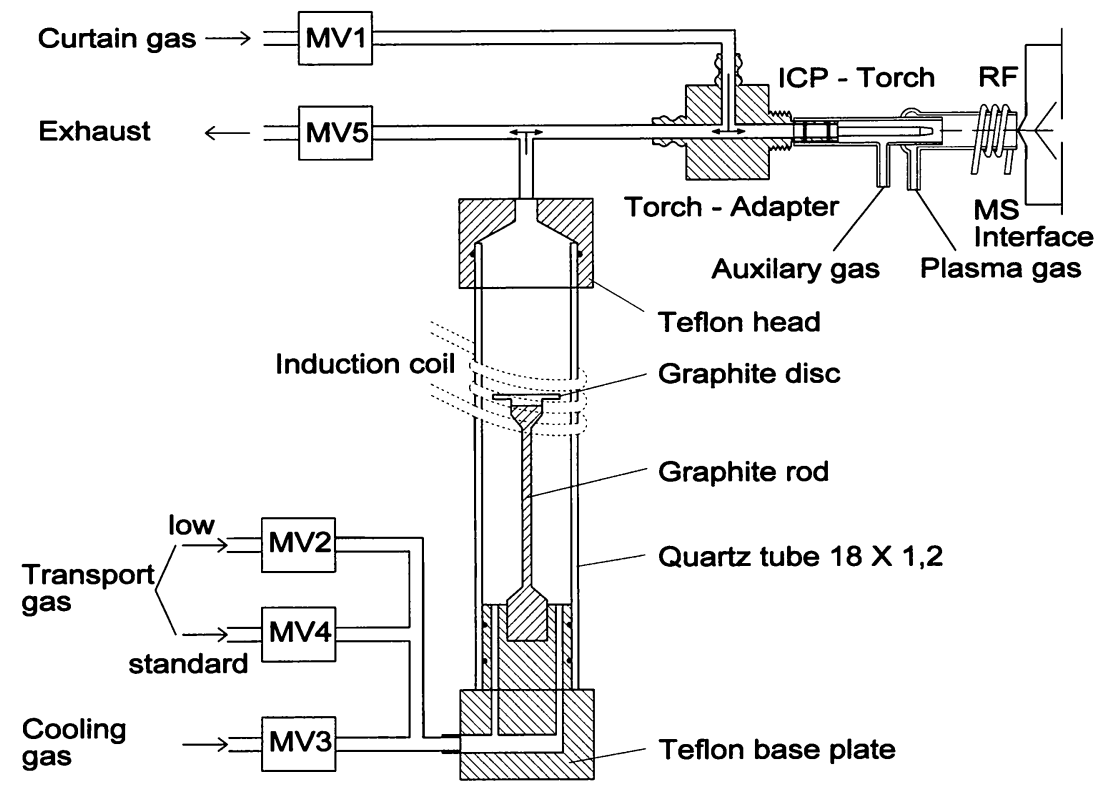

Fig. 2. Schematic diagram of the IHVS coupled to the ICP-TOF interface. Function of magnetic valves (MV): MV 1: Curtain gas $11 \mathrm{~min}^{-1}$; open in stand by or when sample is delivered. MV 2: Transport gas $0.51 \mathrm{~min}^{-1}$; open when solvent or matrix evaporates. MV 4: Transport gas $11 \mathrm{~min}^{-1}$; open to carry the sample vapour to the plasma. MV 3: Cooling gas $21 \mathrm{~min}^{-1}$; open together with MV 2 and MV 4 to chill the graphite workpiece. MV 5: Exhaust valve; open in stand by or together with MV 2 or with MV 3. 
our studies was size fractionation by inertial deposition in a cascade impactor (Ströhlein Instruments, Kaarst, Germany). It was operated by a flow-controlled dry rotary pump and designed to separate particles at cut-off diameters of 0.35 , $0.65,1.1,3.45,7.5,10$, and $16.6 \mu \mathrm{m}$ on eight stages at a flow rate of $2.2 \mathrm{~m}^{3} \mathrm{~h}^{-1}$. To avoid interferences with the subsequent analytical procedure the particles were deposited on cleaned graphite targets, discs of $6 \mathrm{~mm}$ in diameter and $2 \mathrm{~mm}$ thickness in-house manufactured from a rod of pure graphite RW 003 (SGL Carbon Ringsdorff-Werk, Bonn, Germany). The roughness of the graphite surface, as seen in the SEM picture Fig. 3, minimizes the loss of particles due to elastic collisions (bounce off) and permits a sufficient sampling efficiency. No additional adhesive was used. Six graphite targets per stage were fixed between polymethyl methacrylate (PMMA) impaction plates with one disc underneath one nozzle. Before use in the impactor, each disc was cleaned by inductively heatings to $2700{ }^{\circ} \mathrm{C}$ with blank values recorded. Then the discs were stored in well sealed plastic containers and inserted into the cascade impactor under a clean bench (U.S. class 100) at the sampling location. Arctic aerosols were sampled at the German

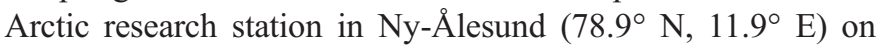
Spitsbergen, Norway in connection to the measurement campaign ASTAR 2004 between May 10 and June 10, 2004. The sampled air volumes per target was 2501 , the sampling time was $24 \mathrm{~h}$. This corresponds to the flow through one nozzle of the multi-jet cascade impactor used. The impactor was installed on top of the roof of the NDSC-building (a laboratory building connected to the Network for Determination of Stratospheric Changes) at a height of about $10 \mathrm{~m}$ above ground level to avoid contaminations from snow drift and local dust soil resuspension.

\subsection{IHVS-ICP-TOF-MS measurements}

Adequate care was given to minimize the uncertainties in IHVS solid sampling measurements. The optimal plasma position was checked by nebulization of aqueous standards before mounting the IHVS to the TOF-MS. An optical pyrometer (Pyrolux II, Prüfgeräte-Werk Medingen, Dresden, Germany) was used to control the temperature of the sample target. To correct a possible drift of the IHVS-ICP-TOF-MS instrument, a liquid standard sample was measured at regular

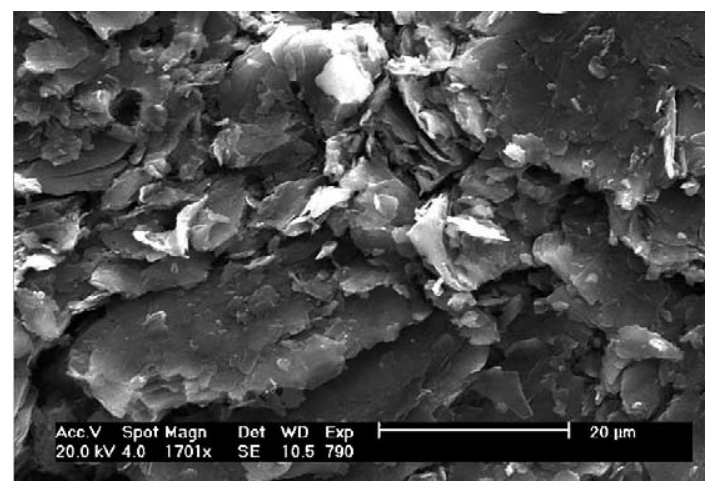

Fig. 3. Graphite surface of an impaction target.
Table 3

Operating program for inductively heated vaporizer

\begin{tabular}{llcll}
\hline Step & Temperature $/{ }^{\circ} \mathrm{C}$ & $\begin{array}{c}\text { Hold } \\
\text { time/s }\end{array}$ & $\begin{array}{l}\text { Gas flow } \\
1 / \mathrm{min}^{-1}\end{array}$ & $\begin{array}{l}\text { Data } \\
\text { acquisition }\end{array}$ \\
\hline Drying & 110 & $8^{+} / 50^{\&}$ & 1.5 & Off \\
Charring & 240 & 10 & 1.5 & On* \\
Vaporize & 2750 & 3.5 & 1 & On \\
Vapour transport & Cool down & 8.5 & 1 & On \\
Cooling & 20 & 160 & 3.5 & Off \\
\hline
\end{tabular}

*Data acquisition triggered $3 \mathrm{~s}$ before the beginning of the vaporization step. ${ }^{+}$Graphite target; ${ }^{\&}$ Solution droplet.

intervals. For the determination of the element content in sampled particles, the loaded graphite targets were transferred one by one into the inductively heated system. After lifting the quartz tube the impaction target is deposited on the graphite workpiece of the vaporizer and the quartz tube is re-fixed on the Teflon base plate. During this procedure the curtain gas (1 $1 \mathrm{~min}^{-1}$ ) prevents the break down of the plasma. The workpiece was stepwise heated according the computer program given in Table 3 and the sample vapor was swept by argon into the center channel of the plasma. The ions generated there were counted after passing the time of flight instrument with settings as given in Table 1. Three different ion mass regions were suppressed, as mentioned above, to avoid the overload of the detector by high ion intensities: (1) mass 12-19 (C- and O-based ions); (2) mass 28-35(N-based ions); (3) mass 38-44 (Ar-based ions). The transient raw-data for 800 sweeps (measuring time $15 \mathrm{~s}$ ) were stored on a removable hard disc and processed on a separate PC. Software developed specifically for this purpose permits individual peak integration at the evaporation time scale. The calculation is made in two steps. In a first step, the 800 sweeps of full mass spectra were summarized for a sum spectrum, without consideration of their temporal succession. The widths of all mass peaks needed for evaluation were chose in this sum spectrum. In a second step the integral value over the selected width of the individual mass

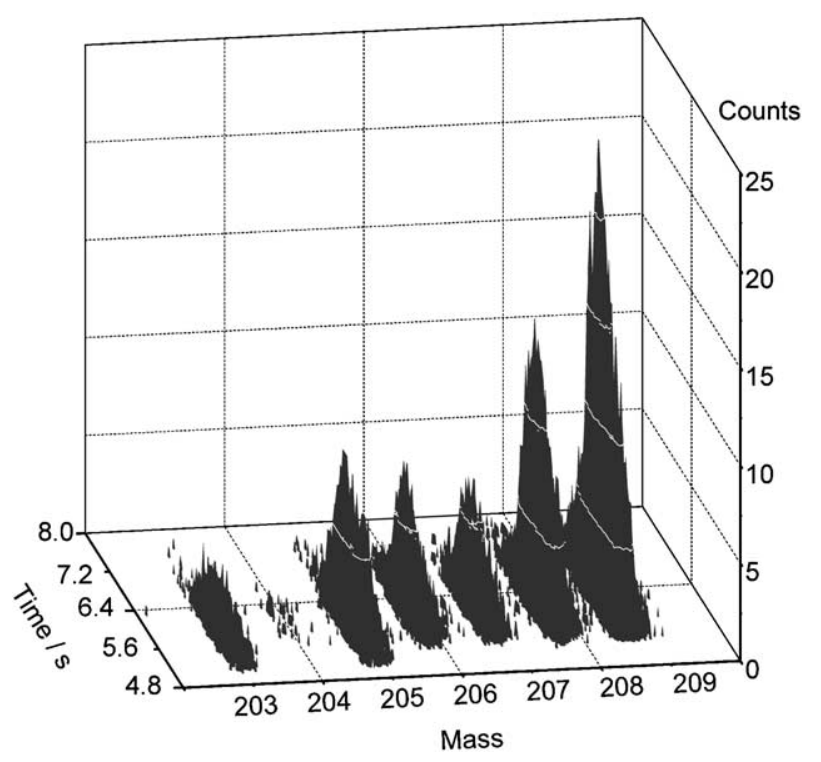

Fig. 4. Section of time resolved mass spectrum. 
Table 4

Measured metal content in arctic aerosol particles, limits of detection and reproducibility of repeated dosage of calibration solution

\begin{tabular}{|c|c|c|c|c|c|c|}
\hline \multirow[t]{2}{*}{ Isotope } & \multicolumn{2}{|c|}{ Background aerosol } & \multicolumn{2}{|c|}{ Aerosol event } & \multirow{2}{*}{$\frac{\mathrm{LOD}}{(3 \sigma)}$} & \multirow{2}{*}{$\frac{\mathrm{RSD}}{(n=24}$} \\
\hline & $d<2.5 \mu \mathrm{m}$ & $d>2.5 \mu \mathrm{m}$ & $d<2.5 \mu \mathrm{m}$ & $d>2.5 \mu \mathrm{m}$ & & \\
\hline pg $\mathrm{m}^{-3}$ & & & & & pg & $\%$ \\
\hline${ }^{7} \mathrm{Li}^{+}$ & $704 \pm 104$ & $878 \pm 111$ & $2728 \pm 327$ & $1218 \pm 277$ & 80 & 2.8 \\
\hline${ }^{59} \mathrm{Co}^{+}$ & $101 \pm 15$ & $185 \pm 25$ & $530 \pm 58$ & $532 \pm 50$ & 13 & 1.7 \\
\hline${ }^{71} \mathrm{Ga}^{+}$ & $99 \pm 12$ & $161 \pm 18$ & $228 \pm 23$ & $290 \pm 27$ & 5 & 3.4 \\
\hline${ }^{88} \mathrm{Sr}^{+}$ & $437 \pm 93$ & $691 \pm 167$ & $883 \pm 170$ & $2454 \pm 479$ & 60 & 7.7 \\
\hline${ }^{106} \mathrm{Pd}^{+}$ & $8 \pm 1.3$ & $23 \pm 3.9$ & $208 \pm 32$ & $350 \pm 56$ & 0.6 & 4.9 \\
\hline${ }^{107} \mathrm{Ag}^{+}$ & $51 \pm 13$ & $66 \pm 16$ & $332 \pm 24$ & $167 \pm 12$ & 3 & 4.2 \\
\hline${ }^{111} \mathrm{Cd}^{+}$ & $257 \pm 45$ & $478 \pm 100$ & $2141 \pm 361$ & $1250 \pm 205$ & 35 & 5.1 \\
\hline${ }^{115} \mathrm{In}^{+}$ & $33 \pm 2.2$ & $66 \pm 4.2$ & $251 \pm 13$ & $127 \pm 6$ & 1.5 & 4.5 \\
\hline${ }^{118} \mathrm{Sn}^{+}$ & $186 \pm 12$ & $455 \pm 31$ & $265 \pm 66$ & $1544 \pm 64$ & 25 & 5.8 \\
\hline${ }^{138} \mathrm{Ba}^{+}$ & $219 \pm 38$ & $765 \pm 106$ & $613 \pm 148$ & $5371 \pm 1243$ & 45 & 7.7 \\
\hline${ }^{205} \mathrm{Tl}^{+}$ & $9 \pm 1.4$ & $16 \pm 2.4$ & $198 \pm 31$ & $29 \pm 4$ & 1.5 & 5.4 \\
\hline${ }^{208} \mathrm{~Pb}^{+}$ & $207 \pm 20$ & $506 \pm 61$ & $5521 \pm 389$ & $2123 \pm 133$ & 10 & 7.5 \\
\hline $\mathrm{ng} \mathrm{m} \mathrm{m}^{-3}$ & & & & & ng & \\
\hline${ }^{23} \mathrm{Na}^{+}$ & $71 \pm 15$ & $80 \pm 17$ & $174 \pm 17$ & $188 \pm 18$ & 0.6 & 3.6 \\
\hline${ }^{25} \mathrm{Mg}^{+}$ & $63 \pm 6.3$ & $105 \pm 10$ & $78 \pm 8$ & $176 \pm 13$ & $5^{*}$ & 2.7 \\
\hline${ }^{27} \mathrm{Al}^{+}$ & $27 \pm 4.3$ & $64 \pm 9$ & $42 \pm 2.3$ & $78 \pm 4.8$ & 0.2 & 2.7 \\
\hline${ }^{53} \mathrm{Cr}^{+}$ & $29 \pm 4.7$ & $54 \pm 8$ & $28 \pm 4.7$ & $96 \pm 19$ & 0.6 & 1.4 \\
\hline${ }^{55} \mathrm{Mn}^{+}$ & $0.59 \pm 0.08$ & $1.2 \pm 0.16$ & $1.9 \pm 0.3$ & $5.7 \pm 1.1$ & 0.02 & 1.9 \\
\hline${ }^{58} \mathrm{Ni}^{+}$ & $2.5 \pm 0.4$ & $9.3 \pm 1.6$ & $13 \pm 1.2$ & $76 \pm 6.3$ & 0.08 & 2.4 \\
\hline${ }^{63} \mathrm{Cu}^{+}$ & $15 \pm 2.4$ & $39 \pm 7.4$ & $45 \pm 12$ & $131 \pm 33$ & 0.2 & 2.4 \\
\hline${ }^{6} \mathrm{Zn}^{+}$ & $6.2 \pm 0.7$ & $11 \pm 1.1$ & $24 \pm 2.2$ & $14 \pm 1.0$ & 0.06 & 12.6 \\
\hline
\end{tabular}

Metal contents are expressed as mean \pm relative standard deviation corresponding to Gaussian statistics.

*Background interference by graphite ${ }^{12} \mathrm{C}-{ }^{13} \mathrm{C}$.

$n=$ number of measurements.

$d=$ aerodynamic diameter.

peak was represented versus the time scale of its temporal succession. By this way a diagram is computed for the temporal course of evaporation of each considered mass. All quantitative data interpreting are based on peak integration at this time-resolved evaporation curve. An example of a timeresolved spectrum calculated from 204,000 single spectra (800 sweeps of 255 spectra) is given in Fig. 4. Shown is a mass section with the isotopes ${ }^{203} \mathrm{Tl}^{+},{ }^{204} \mathrm{~Pb}^{+},{ }^{205} \mathrm{Tl}^{+},{ }^{206} \mathrm{~Pb}^{+},{ }^{207} \mathrm{~Pb}^{+}$,
${ }^{208} \mathrm{~Pb}^{+}$, and ${ }^{209} \mathrm{Bi}^{+}$derived from $5 \mu$ of a solution containing $100 \mu \mathrm{g} / \mathrm{l}$ of each element. Tl with the lowest boiling point evaporates first. The half-width of the peaks is smaller than $1 \mathrm{~s}$ and the $10 \%$ width nearly $2 \mathrm{~s}$.

For calibration of measurements with the graphite target acidic reference solutions were freshly prepared from the ICP Multi-element Standard Merck IV (Merck KgaA, 64271 Darmstadt, Germany) in $0.029 \mathrm{~m} \mathrm{l}^{-1} \mathrm{HNO}_{3}$ (sub-boiling quality). The calibration standards for $\mathrm{Sb}, \mathrm{Sn}, \mathrm{Pd}$, and Ti were prepared by stepwise dilution from stock solution in $0.024 \mathrm{~m}$ $1^{-1} \mathrm{HCl}$. Aliquots of $10 \mu \mathrm{l}$ reference solutions were transferred manually with a micropipette onto the graphite disc on the workpiece. The reproducibility of repeated injections - specified in last column in Table 4-was between $2 \%$ and $7 \%$. When drying or charring the sample a low transport gas flow $\left(0.51 \mathrm{~min}^{-1}\right)$ removes the vapor via the exhaust valve. The argon standard transport gas carries the vaporized sample into the ICP during the heating step. The transport gas flow is limited by the injector tube $(2 \mathrm{~mm} \varnothing)$ of the quartz torch used. For a selected number of elements the signal height was determined as a function of the transport gas flow-rate as it is shown in Fig. 5. For this experiment single stock solutions were diluted for each element. On grounds of different evaporation and ionization conditions varies the maximum intensity from element to element. As a compromise for all measurements a transport gas flow-rate of $11 \mathrm{~min}^{-1}$ was used.

\section{Results and discussion}

As an example of elements determined in Arctic aerosol particles (May 15th) of $2.2 \mu \mathrm{m}$ aerodynamic diameter Fig. $6 \mathrm{~A}$ represents a time integrated full mass spectrum from ${ }^{7} \mathrm{Li}^{+}$ to ${ }^{209} \mathrm{Bi}^{+}$obtained by heating the loaded impaction target of the corresponding impactor stage. In Fig. 6B the spectrum for the same target is shown after subsequent heating. The measured counts of the latter were used in further calculations as correspondent blank value. Hatched are suppressed regions around $\mathrm{C}, \mathrm{O}$ and $\mathrm{H}_{2} \mathrm{O} ; \mathrm{N}_{2}$, and $\mathrm{O}_{2}$; and $\mathrm{Ar}$, ArH. All

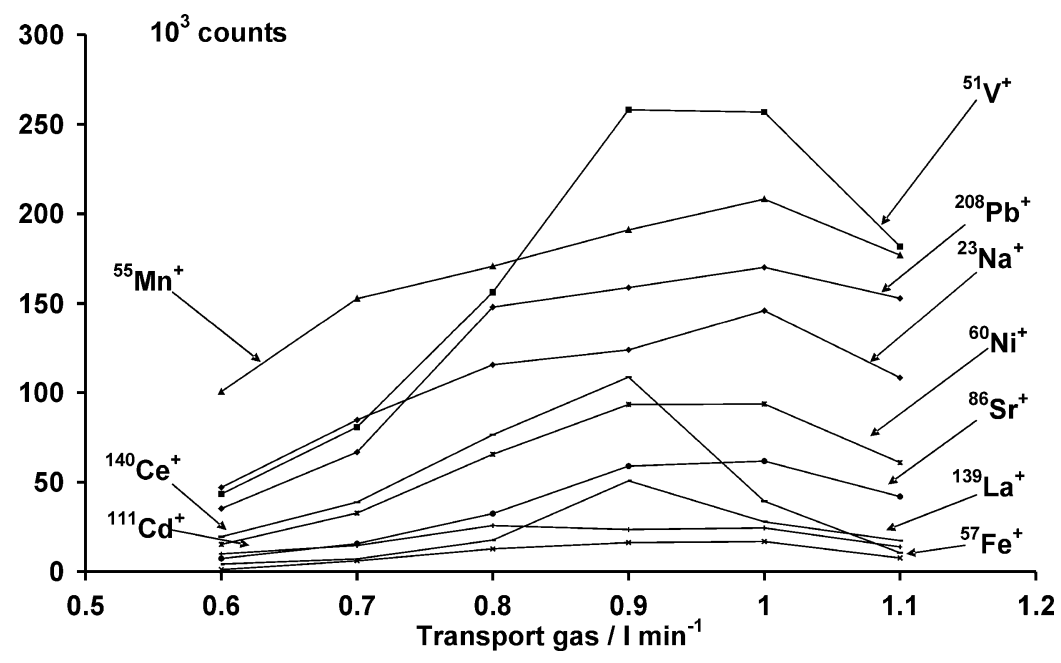

Fig. 5. Signal intensity as a function of transport gas flow-rate. 
major lines are assigned to the corresponding elements or background molecules. Unfortunately a series of molecule interferences overlay isotopes of interest in the mass range between 10 and $80 \mathrm{amu}$. Surprisingly $\mathrm{Pd}, \mathrm{Ag}$, and $\mathrm{Au}$ were detected for aerosol particles in this size range. Impactor samplings, carried out on May 18th, May 27th and June 05th did not show significant differences in the element distribution over the measured particle size spectrum. All three data sets were averaged to calculate a background aerosol distribution. The obtained metal content in particles smaller than $2.5 \mu \mathrm{m}$ aerodynamic diameter - calculated as the sum of the stages $0.35-2.2 \mu \mathrm{m}$ aerodynamic diameter-and the

A
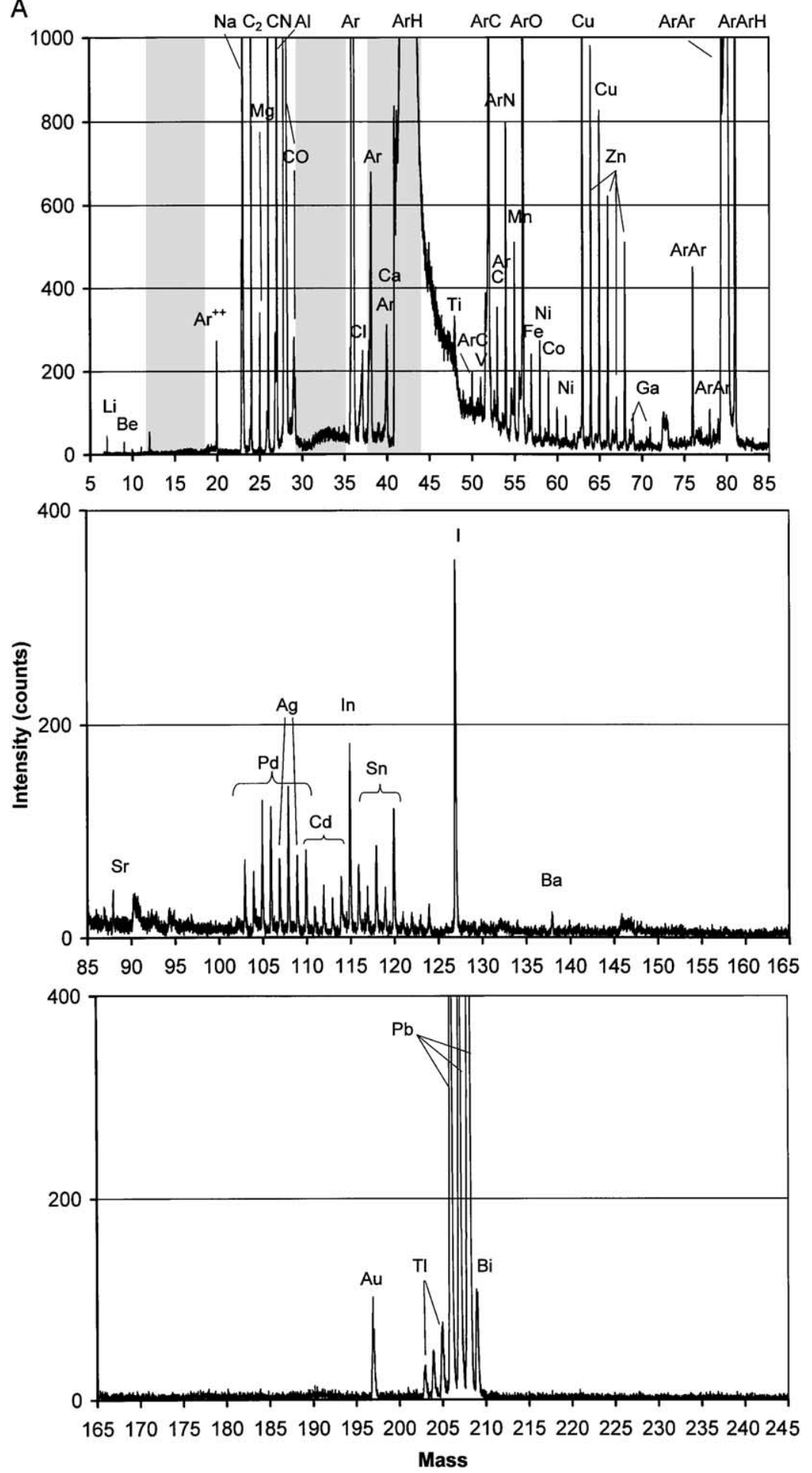

Fig. 6. (A) Full mass spectrum of arctic aerosol particles at $2.2 \mu \mathrm{m}$ aerodynamic diameter (hatched suppressed region). (B) Full mass spectrum of the same sample as in (A) after all substances evaporated (hatched suppressed region). 
B
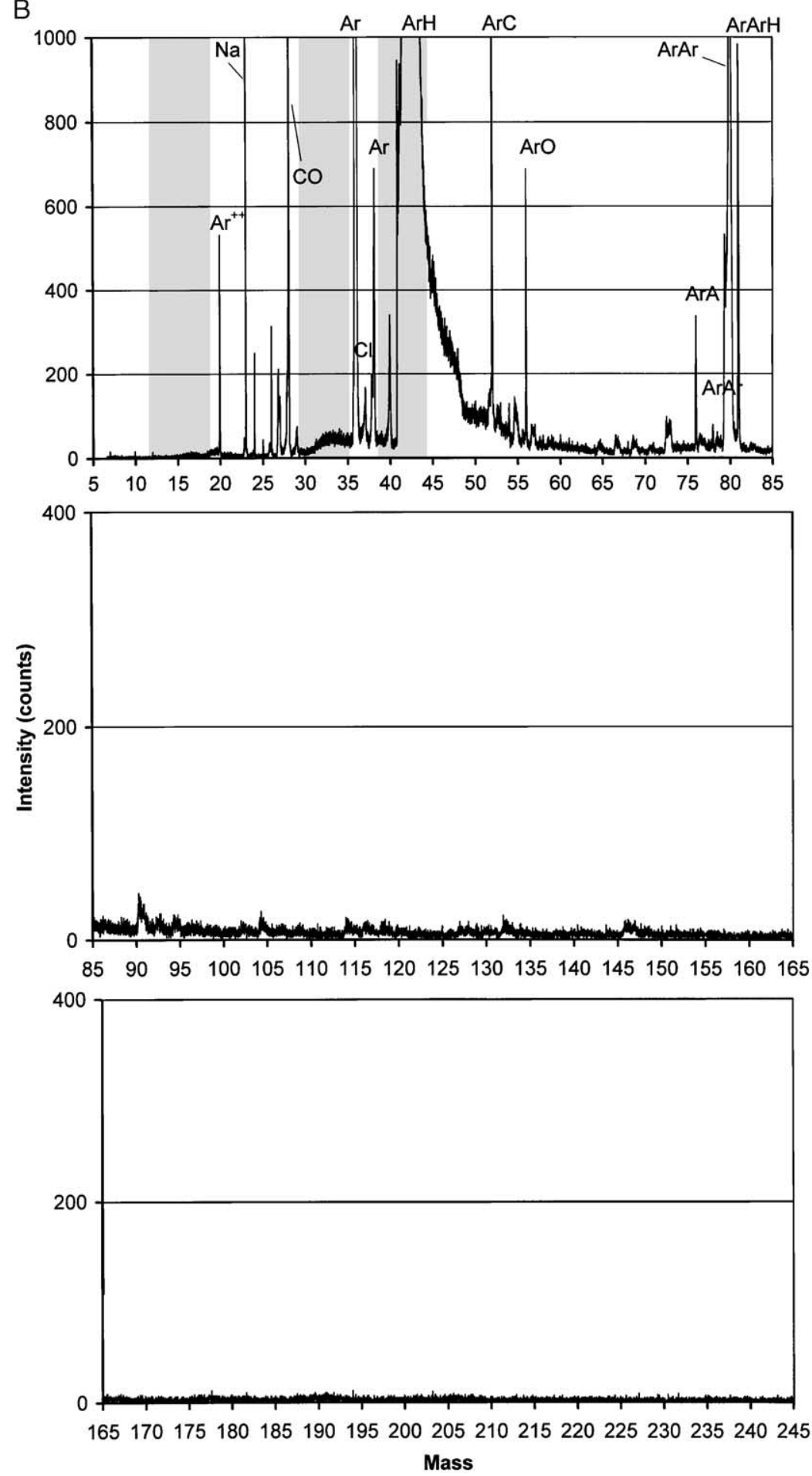

Fig. 6 (continued).

content in particles higher than $2.5 \mu \mathrm{m}$ aerodynamic diameter - calculated as the sum of the stages 3.5-16.6 $\mu \mathrm{m}$ aerodynamic diameter-are summarized in Table 4. The column "aerosol event" in Table 4 contains the measurements on May 15th. Obvious higher element concentrations were measured on this day. Simultaneous measurements of optical aerosol depth (AOD - aerosol optical depth) with a sun photometer at $532 \mathrm{~nm}$ show significant higher aerosol concentrations at May 15th (AOD 0.092) in comparison to May 18th (AOD 0.078), May 27th (AOD 0.049) and June 05th (AOD 0.043). The AOD measurements are described in detail in Herber et al. [36]. The event with higher atmospheric dust loading seems to be responsible for the enriched trace metal concentrations. Taking into account the element composition of the upper earth crust [37] and the sea water [38] sources of trace elements in aerosol particles 

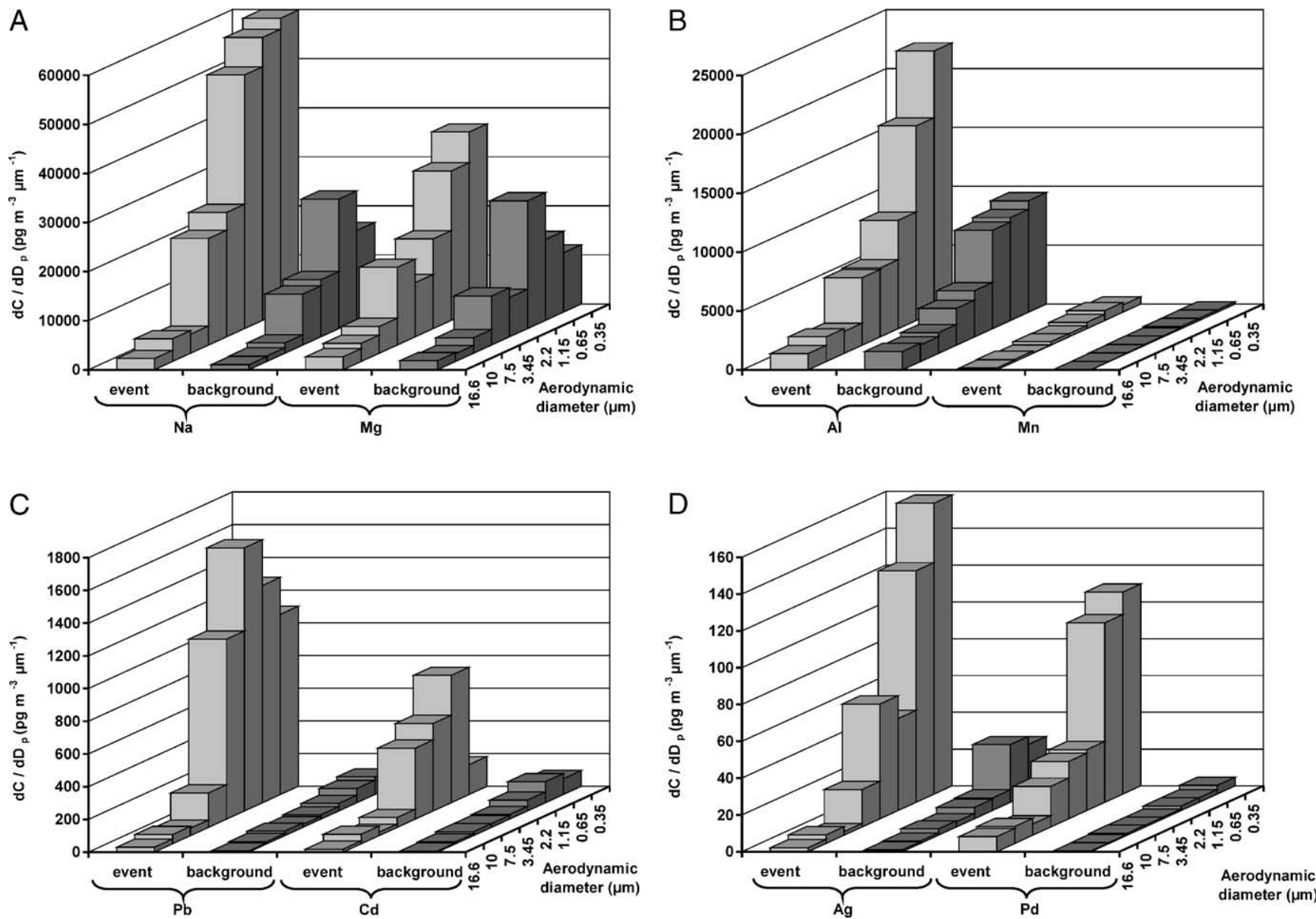

Fig. 7. Normalized particle size distributions (A) marine aerosol. (B) mineral dust. (C) anthropogenic aerosol (D) anthropogenic aerosol.

can be calculated. In Fig. 7 normalized size distributions are exemplarily shown for different tracer elements (element concentrations are normalized to the class width of the aerodynamic diameter): $\mathrm{Na}$ and $\mathrm{Mg}$ for marine sources (Fig. 7A), $\mathrm{Al}$ and $\mathrm{Mn}$ for mineral dust (Fig. 7B) and $\mathrm{Pb}, \mathrm{Cd}, \mathrm{Ag}$, and Pd for anthropogenic influenced aerosol (Fig. 7C, 7D).
It is obvious that the sea salt components as well as the mineral dust components show no significant changes in size distributions during the aerosol event and the background event. Their bulk concentrations are about a factor of two higher in the coarse and in the fine mode at May 15th, which is in a good agreement with the

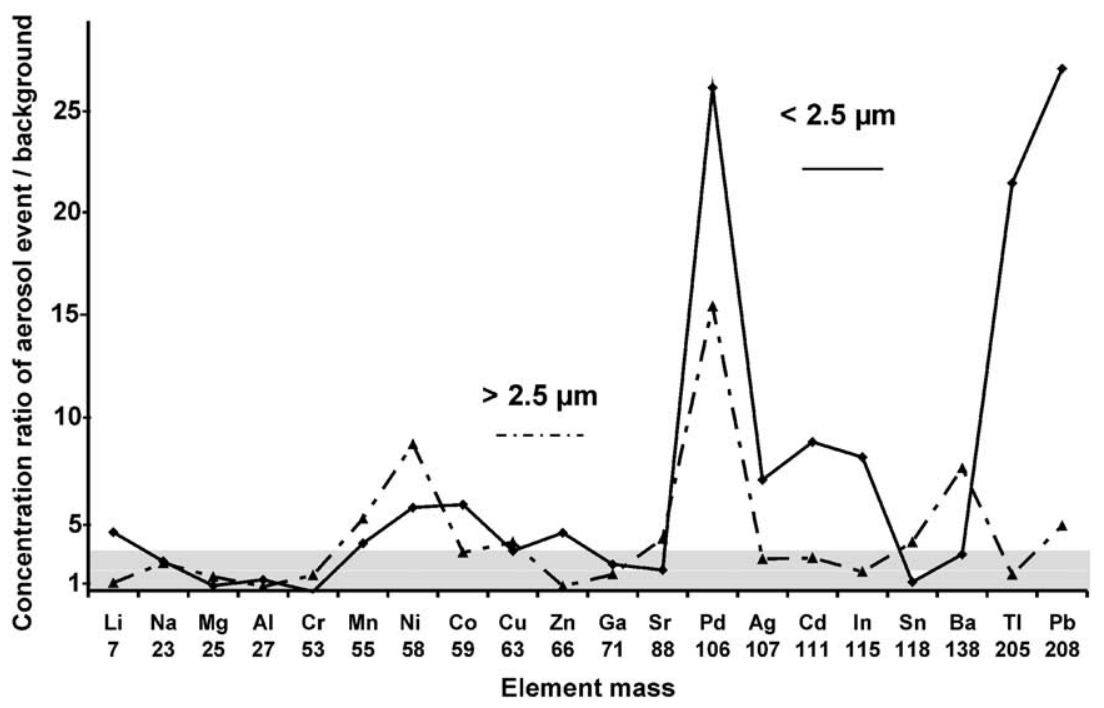

Fig. 8. Element concentration ratio between an aerosol event and a background aerosol. 
measurements of the AOD of 0.092 in comparison to AOD 0.049 at May 27th.

The high aerosol concentration at May 15th is not caused by mineral dust, but more by marine air masses containing a high degree of anthropogenic aerosol. Magnesium and Sodium are slightly enriched, but a high load of anthropogenic material is detected in the aerosol, especially in the size range $<2 \mu \mathrm{m}$ aerodynamic diameter. The element concentration ratio between the aerosol event and the background aerosol is given in Fig. 8 for all measured isotopes. To ensure significant differences between the element concentrations (based on six measurements with $25 \%$ relative standard deviation and a level of significance of $99 \%$ ) their concentration ratio must be greater than two [39]. Assumed a factor of 3 for the positive proof, a significant enrichment of the anthropogenic components $\mathrm{Li}, \mathrm{Mn}, \mathrm{Ni}, \mathrm{Co}, \mathrm{Zn}, \mathrm{Pd}, \mathrm{Ag}, \mathrm{Cd}, \mathrm{In}, \mathrm{Ba}, \mathrm{Tl}, \mathrm{Pb}$ was estimated, up to a factor of 27. Detection limits based on the $3 \sigma$ criterion derived from calibration graphs and 10 blank measurements are also given in Table 4 . The signal variation of the 6 targets per impactor stage ranges between $10 \%$ and $25 \%$ for the elements studied.

\section{Conclusions}

To analyze airborne particles collected with a time resolution of a few hours and fractionated according to size in remote areas like polar regions one needs (1) an efficient sampling system with fast and easy handling, (2) multi-element analysis techniques requiring only minimum sample preparation and (3) analytical instruments with high detection power.

Impaction of particles to high-purity graphite targets and evaporation of the sample direct from the target does not need any preparatory steps. The combination of inductively sample heating and ICP-TOF-MS measurement fulfils in ideal manner the needs for a time resolving measuring system of the mass spectral range from 7 to 270 atomic mass units. The inductively contact free heating of the graphite targets is easy to handle and prevents contaminations by the electrothermal oven housings. The transport of the vaporized sample to the ICP is quick and efficient as seen on the width of time resolved vaporization pulse. Disadvantageous at the present state is the small sample throughput of 12 targets per hour, limited by the long cooldown period. But with the addition of an automated sample insertion system, for example as described in Ref. [40], this problem can be solved.

The possibilities arising from the measurements of time resolved full mass spectra lead to better interpreting of results with simultaneous consideration of element correlations and isotope ratios.

\section{Acknowledgements}

The financial support given by the Senatsverwaltung für Wissenschaft, Forschung und Kultur des Landes Berlin, the Bundesministerium für Bildung und Forschung and the Deutsche Forschungsgemeinschaft (Project Nr. LU 487 / 4 - 1) is gratefully acknowledged.

\section{References}

[1] A.L. Gray, A.R. Date, Inductively coupled plasma source mass spectrometry using continuum flow ion extraction, Analyst 108 (1983) $1033-1050$.

[2] R.S. Houk, Mass spectrometry of inductively coupled plasmas, Anal. Chem. 58 (1986) 97A-105A

[3] D. Beauchemin, Inductively coupled plasma mass spectrometry, Anal. Chem. 76 (2004) 3395-3416.

[4] P.P. Mahoney, Gangquiang Li, G.M. Hieftje, Laser ablation-inductively coupled plasma mass spectrometry with a time-of-flight mass analyser, J. Anal. At. Spectrom. 11 (1996) 401

[5] P.P. Mahoney, S.J. Ray, G.M. Hieftje, Time-of-flight mass spectrometry for elemental analysis, Appl. Spectrosc. 51 (1997) 16A-28A.

[6] R.E. Sturgeon, J.W.H. Lam, A. Saint, Analytical characteristics of a commercial ICP orthogonal acceleration time-of-flight mass spectrometer (ICP-TOFMS), J. Anal. At. Spectrom. 15 (2000) 607-616.

[7] M. Guilhaus, D. Selby, V. Mlynski, Orthogonal acceleration time-of-flight mass spectrometry, Mass Spectrom. Rev. 19 (2000) 65-107.

[8] X. Tian, H. Emteborg, F.C. Adams, Analytical performance of axial inductively coupled plasma time of flight mass spectrometry (ICPTOFMS), J. Anal. At. Spectrom. 12 (1999) 1807-1814.

[9] D.P. Myers, G. Li, P. Yang, G.M. Hieftje, An inductively coupled plasmatime-of-flight mass spectrometer (ICP-TOFMS) for elemental analysis: Part I. optimization and characteristics, J. Am. Soc. Mass Spectrom. 5 (1994) 1008-1016.

[10] E. Hoffmann, C. Lüdke, J. Skole, H. Stephanowitz, J. Wollbrandt, W. Becker, New methodical and instrumental developments in laser ablation inductively coupled plasma mass spectrometry, Spectrochim. Acta Part B 57 (2002) $1535-1545$.

[11] R.F. Browner, A.W. Boorn, Sample introduction: the Achilles' heel of atomic spectroscopy, Anal. Chem. 56 (1984) 786A-798A.

[12] A.L. Gray, Solid sample introduction by laser ablation for inductively coupled plasma source mass spectrometry, Analyst 110 (1985) $551-556$.

[13] J. Westheide, J.S. Becker, R. Jäger, H.J. Dietze, J.A.C. Broekaert, Analysis of ceramic layers for solid oxide fuel cells by laser ablation inductively coupled plasma mass spectroscopy, J. Anal. At. Spectrom. 11 (1996) 661-666.

[14] E. Hoffmann, H. Stephanowitz, E. Ullrich, J. Skole, C. Lüdke, B. Hoffmann, Investigation of mercury migration in human teeth using spatially resolved analysis by laser ablation-ICP-MS, J. Anal. At. Spectrom. 15 (2000) 663-667.

[15] B.V. L'vov, The investigation of atomic absorption spectra by complete vaporization of the sample in a graphite cuvette, Spectrochim. Acta Part B 39 (1984) 159-166.

[16] W. Frech, Recent developments in atomizers for electrothermal atomic absorption spectrometry, Fresenius' J. Anal. Chem. 355 (1996) 475-486.

[17] M.M. Lamoureux, D.C. Gregoire, C.L. Chakrabarti, D.M. Goltz, Modification of a commercial elektrothermal vaporizer for sample introduction into an inductively coupled plasma mass spectrometer: 1 . Characterization, Anal. Chem. 66 (1994) 3208-3222.

[18] M. Resano, M. Verstraete, F. Vanhaecke, L. Moens, Evaluation of the multi-element capabilities of electrothermal vaporization quadrupolebased ICP mass spectrometry, J. Anal. At. Spectrom. 16 (2001) $1018-1027$.

[19] E. Björn, D.C. Baxter, W. Frech, Calibration errors due to variations in peak characteristics in the measurement of transient signals by inductively coupled plasma-scanning mass spectrometry, J. Anal. At. Spectrom. 17 (2002) $1582-1588$.

[20] T. Kantor, Interpreting some analytical characteristics of thermal dispersion methods used for some sample introduction in atomic spectrometry, Spectrochim. Acta Part B 43 (Nos 9-11) (1988) 1299-1320.

[21] D.M. Goltz, C.D. Skinner, E.D. Salin, Sample introduction for inductively coupled plasma atomic emission spectrometry using an inductively heated vaporizer, Spectrochim. Acta Part B 53 (1998) 1139-1147.

[22] M.E. Rybak, E.D. Salin, Direct determination of metals in soils and sediments by induction heating-electrothermal vaporization (IH-ETV) 
inductively coupled plasma-optical emission spectrometry (ICP-OES), Appl. Spectrosc. 55 (2001) 816-821.

[23] D.M. Goltz, E.D. Salin, An inductively heated vaporizer for inductively coupled plasma mass spectrometry, J. Anal. At. Spectrom. 12 (1997) $1175-1180$.

[24] J.M. Ren, M.E. Rybak, E.D. Salin, Elimination of arcing in induction heating-electrothermal vaporization (IH-ETV) for sample introduction into inductively coupled plasmas, J. Anal. At. Spectrom. 18 (2003) $485-486$.

[25] R. Treffeisen, A. Herber, J. Ström, M. Shiobara, T. Yamanouchi, S. Yamagata, K. Holmén, M. Kriews, O. Schrems, Interpretation of Arctic aerosol properties using cluster analysis applied to observations in the Svalbard area, Tellus 56B (2004) 457-476.

[26] E. Gard, J.E. Mayer, B.D. Morrical, T. Dienes, D.P. Fergenson, K.A. Prather, Real-time analysis of individual atmospheric particles: design and performance of a portable ATOFMS, Anal. Chem. 69 (1997) 4083-4091.

[27] T. Adam. Characterization of Size Fractionated Aerosol Particles from the East Atlantic and Spitsbergen, Diploma Theses (2001) University Regensburg, Germany.

[28] C. Lüdke, E. Hoffmann, J. Skole, S. Artelt, Particle analysis of car exhaust by ETV-ICP-MS, Fresenius, J. Anal. Chem. 355 (1996) 261-263.

[29] C. Lüdke, E. Hoffmann, J. Skole, Determination of trace-metal concentrations in size-classified atmospheric particles by ETV-ICP-MS, Fresenius, J. Anal. Chem. 359 (1997) 399-403.

[30] C. Lüdke, E. Hoffmann, J. Skole, M. Kriews, Determination of trace metals in size fractionated particles from arctic air by electrothermal vaporization inductively coupled plasma mass spectrometry, J. Anal. At. Spectrom. 14 (1999) 1685-1690.
[31] B.A. Mamyrin, Time-of-flight mass spectrometry (concepts, achievements, and prospects), Int. J. Mass Spectrom. 206 (3) (2001) 251-266

[32] D.J. Douglas, S.D. Tanner, Fundamental considerations in ICPMS, in: A Montaser (Ed.), Inductively Coupled Plasma Mass Spectrometry, WileyVCH, 1998.

[33] S. Zinn, S.L. Semiatin, Elements of Induction Heating: Design, Control and Applications, Electric Power Research Institute, Palo Alto, 1988.

[34] M. Von Ardenne, G. Musiol, S. Reball, Effekte Der Physik Und Ihre Anwendungen, VEB Deutscher Verlag der Wissenschaften, Berlin, 1989.

[35] R.D. Ediger, S.A. Beres, The role of chemical modifiers in analyte transport loss interferences with electrothermal vaporization ICP-mass spectrometry, Spectrochim. Acta Part B 47 (7) (1992) 907-922.

[36] A. Herber, L.W. Thomason, H. Gernandt, U. Leiterer, D. Nagel, K.H Schulz, J. Kaptur, T. Albrecht, J. Notholt, Continuous day and night aerosol optical depth observations in the Arctic between 1991 and 1999, J. Geophys. Res. 107 (D10) (2002).

[37] K.H. Wedepohl, The composition of the continental crust, Geochim. Cosmochim. Acta 59 (1995) 1217-1232.

[38] H.D. Holland, The Chemistry of Atmosphere and Oceans, First edition, John Wiley and Sons, New York, 1978.

[39] K. Doerffel, Statistik in der Analytischen Chemie, VEB Deutscher Verlag für Grundstoffindustrie, Leipzig, 1966.

[40] W.E. Pettit, G. Horlick, An automated sample insertion system for the inductively coupled plasma, Spectrochim. Acta Part B 41 (7) (1986) $699-712$. 